\title{
TELEDETECCIÓN ESPACIAL APLICADA A LA BÚSQUEDA DE RESTOS de la Estancia San Miguel del Carcarañá
}

\author{
Fabián Bognanni ${ }^{1}(\mathrm{UNLu})$, Mónica P. Valentini², Mariano Darigo², \\ Matías Warr² y María Lara Moschetoni²
}

\begin{abstract}
Resumen
De acuerdo a Gebhard la teledetección es comúnmente definida como "el registro e interpretación de información sobre rasgos u objetos sin estar en contacto con ellos". En el caso de aplicación de la teledetección al campo de la Arqueología, cabe mencionar que el principio de detección remota se utiliza para la identificación, análisis e interpretación de objetos, rasgos y/o contextos culturales o naturales que permitan obtener, de manera directa o indirecta, información resultante de actividades socio-culturales pasadas.

Sobre la ubicación de los restos de los posibles constructivos de lo que fuera el casco principal de la Estancia Jesuita de San Miguel del Carcarañal y sus alrededores, hemos implementado el análisis del territorio a través de la teledetección, esperando que la utilización de la técnica nos permita ser más precisos en la ubicación de los constructivos a la hora de las posibles excavaciones. Se presentan los materiales utilizados, el método y técnicas aplicadas, seguidas de los resultados logrados.
\end{abstract}

Palabras clave: detección remota, registro, restos culturales

\begin{abstract}
According to Gebhard, remote sensing is commonly defined as "the recording and interpretation of information about features or objects without being in contact with them". In the case of the application of remote sensing to the field of archeology, it is worth mentioning that the principle of Remote sensing is used for the identification, analysis and interpretation of objects, traits and / or cultural or natural contexts that allow to obtain, directly or indirectly, information resulting from past socio-cultural activities.

Regarding the location of the remains of the possible constructions of what was the main hull of the Jesuit Estancia of San Miguel del Carcarañal and its environs, we have implemented the analysis through remote sensing. The materials used, the method and techniques applied are presented, followed by the results achieved.
\end{abstract}

Keywords: Remote sensing, registration, Cultural remains

\footnotetext{
${ }^{1}$ Universidad Nacional de Luján; ${ }^{2}$ Universidad Nacional de Rosario, mopavalentini@gmail.com
} 


\section{Introducción}

Los jesuitas llegaron a la ciudad de Santa Fe en 1610, fundaron la iglesia y el colegio de La Inmaculada. Desde el arribo de la Orden a la Provincia de Santa Fe la posesión de tierras (a partir de diferentes vías: legados, compras o merced) le permitieron conformar un significativo sistema de estancias, el más importante de toda la provincia. Este no fue un hecho aislado ya que durante los siglos XVII y XVIII gestionaron emprendimientos agrícolas y mineros en toda América hispánica. Como en otros casos, la actividad desplegada por los jesuitas en Santa Fe estuvo apoyada en un conjunto de establecimientos rurales que contribuyeron a su sustento. En el año 1719 los jesuitas adquieren al vecino de Santa Fe, Maestre de Campo Antonio de Vera Muxica, veinte leguas a ambos lados de la desembocadura del Carcarañá. Las tierras incluían 3200 yeguas de vientre y 250 burros hechores. Claramente el perfil productivo de la nueva estancia, que denominarían San Miguel del Carcarañal, tuvo como objetivo la cría de mulas convirtiéndose en el establecimiento productivo más importante de la provincia.

Emplazada sobre la costa sur del río Carcarañá, la estancia San Miguel fue un enclave productivo de la Compañía de Jesús para proveer de ganado mular a la zona ya que comerciaban las mulas para el transporte, no solo en el área directa de influencia, sino para proveer de las mismas en el traslado de mercancías en el área. Significando también la ocupación del territorio santafecino hacia el sur en un lugar estratégico en la ruta hacia el Alto Perú, las misiones del norte y el oeste.

El sitio pone de manifiesto una compleja trama de relaciones: reducción de indios, utilización de esclavos, control de línea de frontera (interna) como consecuencia de la apropiación de los espacios indígenas resultado de la expansión europea sobre estos territorios.

De acuerdo a Gebhard (2002), la teledetección es comúnmente definida como "el registro e interpretación de información sobre rasgos u objetos sin estar en contacto con ellos. El término teledetección ("remotesensing") incluye al principio físico de la detección remota y está restringido a los métodos que emplean energía electromagnética en forma de luz, calor y ondas de radio, para detectar y medir características de los objetos" (Gebhard, 2002 Ms). En el caso de aplicación de la teledetección al campo de la Arqueología, cabe mencionar que el principio de detección remota se utiliza para la identificación, análisis e interpretación de objetos, rasgos y/o contextos culturales o naturales que permitan obtener, de manera directa o indirecta, información resultante de actividades socio-culturales pasadas (Bognanni, 2015). La aplicación de este conjunto de técnicas no debe tomarse como la panacea del análisis espacial en Arqueología aunque, a lo largo de las últimas décadas, ha demostrado ser muy útil y provechosa en las distintas instancias de investigación. Por ello, es importante destacar dos "máximas" que se deben tener en cuenta en cualquier investigación arqueológica que intente utilizar la teledetección espacial:

1. Cada problema arqueológico es único y debe ser analizado con las imágenes que mejor se ajusten al tema de estudio. No todas las imágenes son útiles debido a que los diferentes sensores (de los tantos satélites) tienen características técnicas distintas que pueden o no ajustarse a las necesidades de la investigación. En este contexto es importante resaltar las diferencias en las escalas de análisis y las consecuentes posibilidades de resolución de cada sensor (espacial, temporal, radiométrica y espectral).

2. El trabajo de campo es ineludible para la contrastación de la información obtenida mediante el sensoriamiento remoto. Para esto basta recordar la célebre frase del lingüista Alfred Korzybski (y popularizada por Gregory Bateson) "el mapa no es el territorio".

Teniendo en cuenta estos recaudos, se presentan los materiales utilizados y el método y técnicas aplicadas, seguidas de los resultados logrados. 


\section{Materiales}

Las imágenes utilizadas en este trabajo provienen del satélite estadounidense Landsat 7 ETM+ (Enhanced Thematic Mapper) de la órbita Path 227 y Row 083 con fecha de toma del 18 de febrero de 2006 y las bandas utilizadas corresponden al espectro visible (bandas 1, 2 y 3), además de las bandas 4, 5 y 7 (infrarrojo cercano y medio) y la banda 8 de carácter pancromático. También se usaron imágenes del satélite CBERS 2B (China-Brazi 1Environment Resources Satellite) con el sensor HRC (High Resolution Camera) de características pancromáticas. La órbita del satélite es Path 166 y Row 137 con fechas de toma del 8 de mayo de 2009. También se utilizaron imágenes RGB (espectro visible) de alta resolución del Google Earth. Para mayor información acerca de las características de estos satélites se presenta la Tabla 1 .

\section{Tabla 1.}

Comparación de características de distintos satélites y sensores

\begin{tabular}{|c|c|c|c|c|c|}
\hline Satélite & CBERS 2B & & LANDSAT 7 & GEOEYE I & QUICKBIRD \\
\hline Sensor & $\begin{array}{l}\text { HRC } \\
\text { Resolution } \\
\text { Camera) }\end{array}$ & (High & $\begin{array}{l}\text { ETM+ } \\
\text { (EnhacedTematicMapper) }\end{array}$ & (Google Earth) & (Google Earth) \\
\hline $\begin{array}{l}\text { Resolución } \\
\text { Radio } \\
\text { métrica }\end{array}$ & 8 bits & & 8 bits & 11 bits & 11 bits \\
\hline $\begin{array}{l}\text { Resolución } \\
\text { Temporal }\end{array}$ & 130 días & & 16 días & 3 días & Entre 2 y 4 días \\
\hline $\begin{array}{l}\text { Resolución } \\
\text { Espacial }\end{array}$ & $2,7 \mathrm{~m}$ & & $\begin{array}{l}30 \\
(\mathrm{~B} 660 \mathrm{~m} ; \mathrm{B} 815 \mathrm{~m})\end{array}$ & $\begin{array}{l}\text { Pan: } \quad 0,41 \mathrm{~m} \\
\text { Multiespectral: } \\
1,65 \mathrm{~m}\end{array}$ & $\begin{array}{l}\text { Pan: } \quad 0,61 \quad m \\
\text { Multiespectral: } \\
2,44 \mathrm{~m}\end{array}$ \\
\hline $\begin{array}{l}\text { Ancho de } \\
\text { faja }\end{array}$ & $27 \mathrm{~km}$ (nadir) & & $185 \mathrm{~km}$ & $15,2 \mathrm{~km}$ & $16,5 \mathrm{~km}$ \\
\hline $\begin{array}{l}\text { Resolución } \\
\text { Espectral: } \\
\text { Banda } 1\end{array}$ & $\begin{array}{l}0,50-0,80 \\
\text { (Pan) }\end{array}$ & $\mu \mathrm{m}$ & $0,45-0,52 \mu \mathrm{m}(\mathrm{A})$ & $\begin{array}{l}0,45-0,80 \quad \mu \mathrm{m} \\
(\text { Pan) }\end{array}$ & $\begin{array}{l}0,445-0,90 \\
(\operatorname{Pan})\end{array}$ \\
\hline Banda 2 & & & $0,52-0,60 \mu \mathrm{m}(\mathrm{V})$ & $0,45-0,51 \mu \mathrm{m}(\mathrm{A})$ & $0,45-0,52 \mu \mathrm{m}(\mathrm{A})$ \\
\hline Banda 3 & & & $0,63-0,69 \mu \mathrm{m}(\mathrm{R})$ & $0,51-0,58 \mu \mathrm{m}(\mathrm{V})$ & $0,52-0,60 \mu \mathrm{m}(\mathrm{V})$ \\
\hline Banda 4 & & & $0,76-0,90 \mu \mathrm{m}(\mathrm{IRc})$ & $0,655-069 \mu \mathrm{m}(\mathrm{R})$ & $0,63-069 \mu \mathrm{m}(\mathrm{R})$ \\
\hline Banda 5 & & & $1,55-1,75 \mu \mathrm{m}(\mathrm{IRm})$ & $\begin{array}{l}0,78-0,92 \\
\text { (IRc) }\end{array}$ & $0,76-0,90 \mu \mathrm{m}(\mathrm{IRc})$ \\
\hline Banda 6 & & & $10,4-12,5 \mu \mathrm{m}($ IR t $)$ & & \\
\hline Banda 7 & & & $2,09-2,35 \mu \mathrm{m}(\mathrm{IRm})$ & & \\
\hline Banda 8 & & & $0,52-0,90 \mu \mathrm{m}$ (Pan) & & \\
\hline
\end{tabular}


Para la aplicación de los filtros y demás técnicas de análisis digital se utilizó el software ENVI 4.2., mientras que para el realce y mejoramiento de las imágenes se utilizó el Adobe Photoshop CS.

\section{Método}

Se realizó una búsqueda sistemática de rasgos con potencial interés arqueológico (principalmente posibles restos de edificaciones) a través de las diferentes imágenes de los distintos satélites. Principalmente se siguen los lineamientos generales de la propuesta metodológica establecida por Bognanni 2015.

Se aplicaron distintos filtros a las imágenes de los diferentes satélites y sensores, ya sean de resolución media o alta. Se analizaron las propiedades físicas de diferentes rasgos de acuerdo a distintas composiciones entre bandas. También se utilizó la morfología matemática para la identificación de rasgos geométricos aunque no se obtuvieron resultados de relevancia. A su vez, se aplicaron distintas operaciones, denominadas "filtros", que tienen la finalidad de eliminar la variabilidad de una imagen al calcular un nuevo valor de cada pixel o celda (nivel digital) a través de determinadas funciones que se aplican sobre de los valores de los pixeles contiguos dando como resultado, con frecuencia aunque no necesariamente, algún tipo de promedio ponderado (Conolly y Lake 2009). La finalidad de estas operaciones es modificar los valores existentes para incrementar o reducir la autocorrección espacial entre celdas vecinas y de esta manera aislar ciertos componentes de interés. La aplicación del filtro se lleva a cabo por medio de un núcleo o matriz numérica cuadrada que se desplaza a través de la imagen modificando los valores de los niveles digitales centrales originales.

Principalmente se aplicaron tres tipos de técnicas de filtrado. En primer lugar, los filtros más utilizados son los denominados "filtros de paso bajo" y "filtros de paso alto". Los primeros tienden a aislar el componente de homogeneidad de la imagen provocando una reducción en la correlación entre celdas vecinas y de esta manera "suavizan" la variabilidad local o "ruido" resultando, en término visuales, en una imagen menos nítida y más difuminada (Chuvieco 1990). Los segundos provocan el efecto contrario, refuerzan la variabilidad local por medio de la ponderación del valor central y en detrimento de los valores externos, dando como resultado un mayor contraste espacial. En segundo lugar se usaron los "filtros de detección de bordes", como el llamado "Laplace". Éstos son particularmente importantes en nuestro caso de estudio ya que son muy útiles para la detección de bordes y líneas sin importar la dirección y se caracterizan por ponderar el valor de pixeles de manera que se destaquen las localizaciones donde se hallan cambios significativos de valores. A su vez, existen otros filtros como el denominado "Sobel", que tiene características no lineales y que también es comúnmente utilizado para la detección de bordes. Por último, cabe destacar los "filtros direccionales" que actúan en el realce de bordes que poseen componentes específicos de dirección (gradientes) que pueden ir de $0^{\circ}$ a $360^{\circ}$. Esta posibilidad es que los hace muy útiles para la detección de rasgos lineales como construcciones arquitectónicas e incluso sendas o caminos en desuso.

Por otro lado, las combinaciones entre bandas de cada satélite permiten que se vinculen en una misma imagen, diferentes canales (rojo, verde y azul) con distintas longitudes de onda. De esta forma, por ejemplo, obtenemos una imagen con colores "reales" con la combinación de las bandas 3, 2 y 1 del satélite Landsat 7 ETM+. Otras combinaciones utilizan bandas sensibles a longitudes de ondas no visibles (es decir, principalmente superiores al rango de aproximadamente 0,4 a $0,7 \mu \mathrm{m}$-espectro visible-), resultando en colores "falsos". En síntesis, la posibilidad de combinación entre las bandas es variada y depende del número de estas, rango de longitud de onda y, principalmente de los objetivos de cada estudio y el contexto ambiental de la zona. 


\section{Resultados}

\section{Zona de interés 1}

Respecto a la información inicial, provista por el equipo de trabajo, acerca del lugar posible de ubicación de la iglesia de la Estancia San Miguel de Carcarañá, se puede reconocer (Figura 1) un rasgo en una imagen pancromática del Satélite CBERS 2B, sensor HRC (con fecha de toma 8/5/2009). El rasgo no puede considerarse positivo, en esta instancia de trabajo, como parte del contexto buscado pero, al menos, es un punto de interés para este fin.

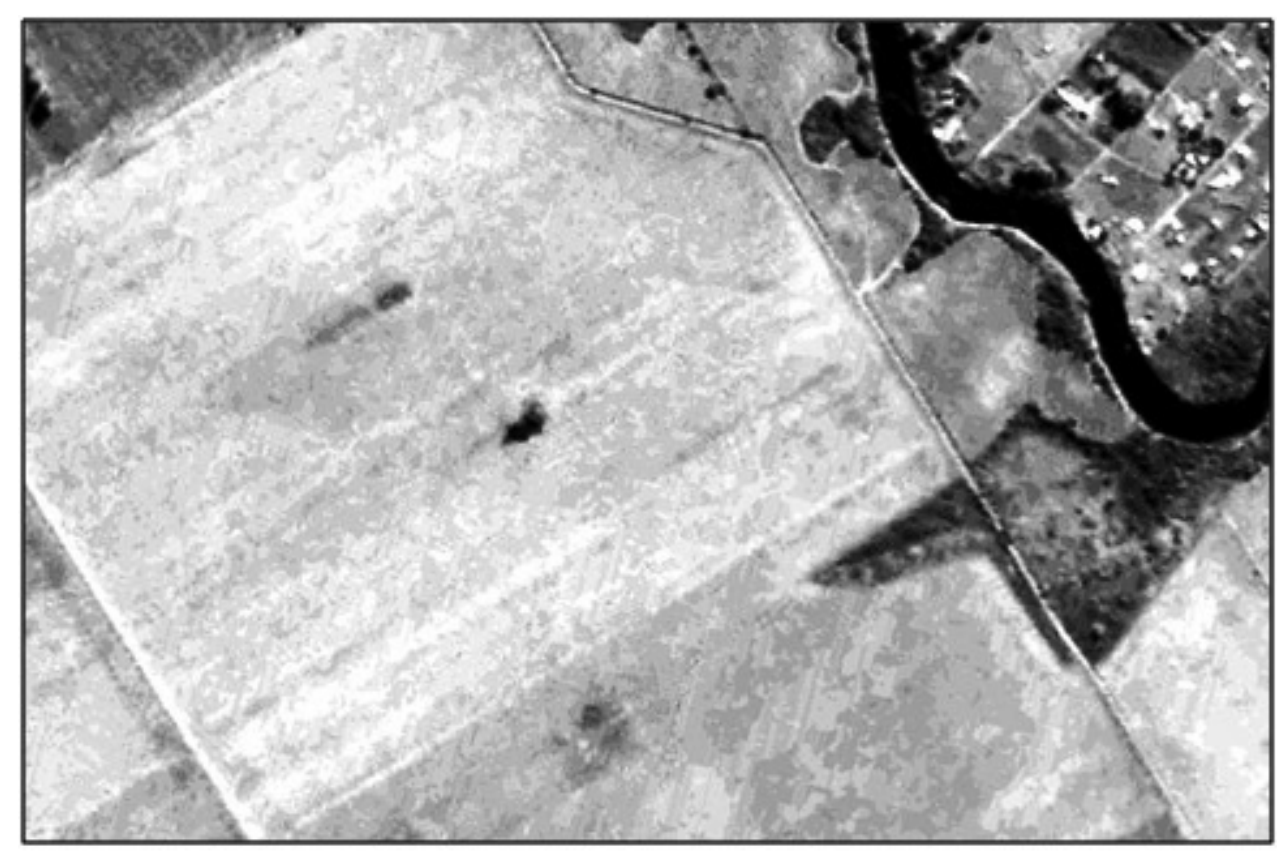

Figura 1. Imagen CBERS 2B HRC pancromática original

En la Figura 2 se presenta la misma imagen pero con realces digitales. Se realizó una modificación del brillo y el contraste seguida de una transformación realizada sobre la base de la ecualización del histograma. El efecto de este realce se traduce en un aumento del contraste de la imagen, con su consecuente mejora en la calidad. 


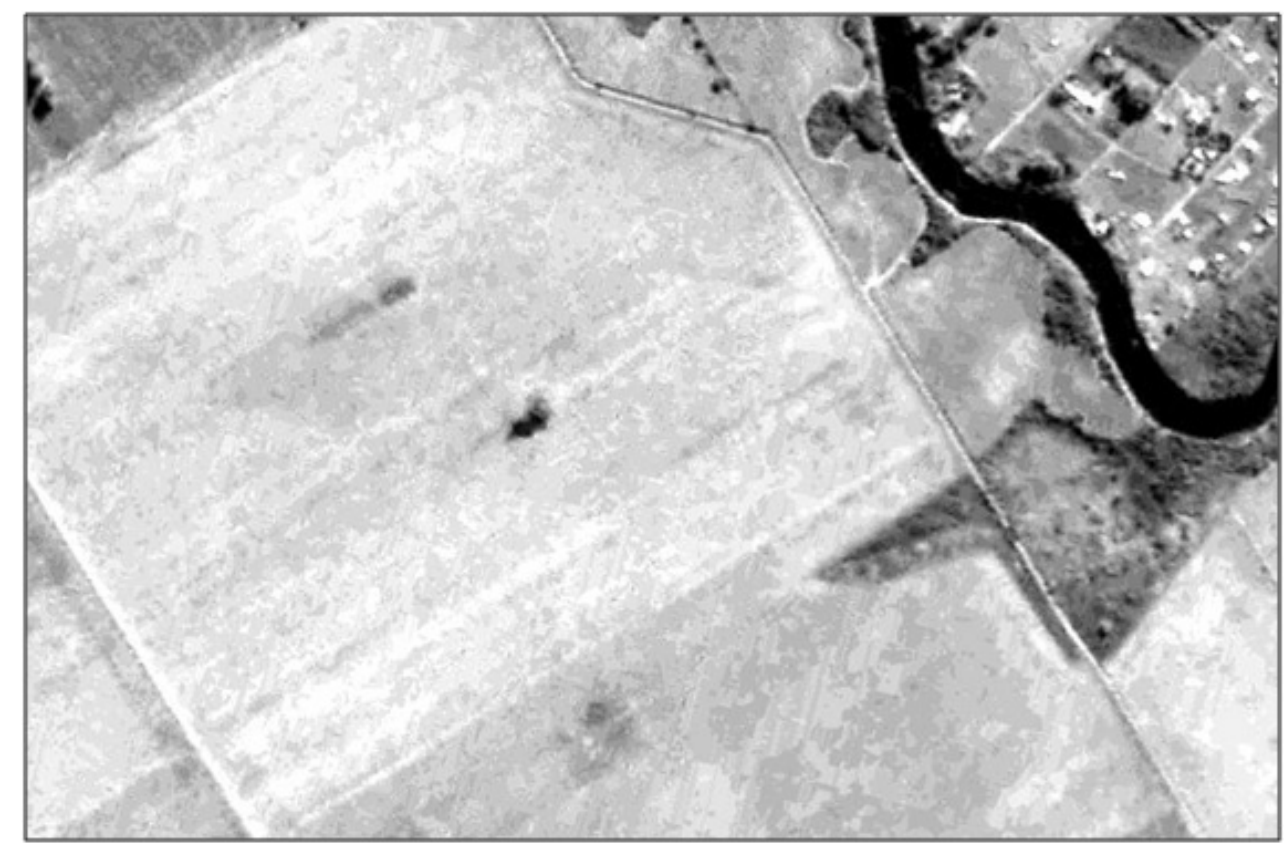

Figura 2. Imagen pancromática con realces en brillo y contraste y ecualización del histograma

Sobre la imagen original, también se aplicaron otros procesos digitales a fin de realizar el realce de rasgos potenciales. En la Figura 3 se aplicó un filtro direccional con un ángulo de $315^{\circ}$ (aplicado por medio de una matriz de $3 \times 3$ pixeles) seguido de un proceso de inversión. Esta última acción se lleva a cabo al transformar cada canal en su negativo y al resultado de esto se le resta la matriz original. Finalmente, para una mayor definición de los rasgos, se ajustó el brillo y contraste de la imagen 2.

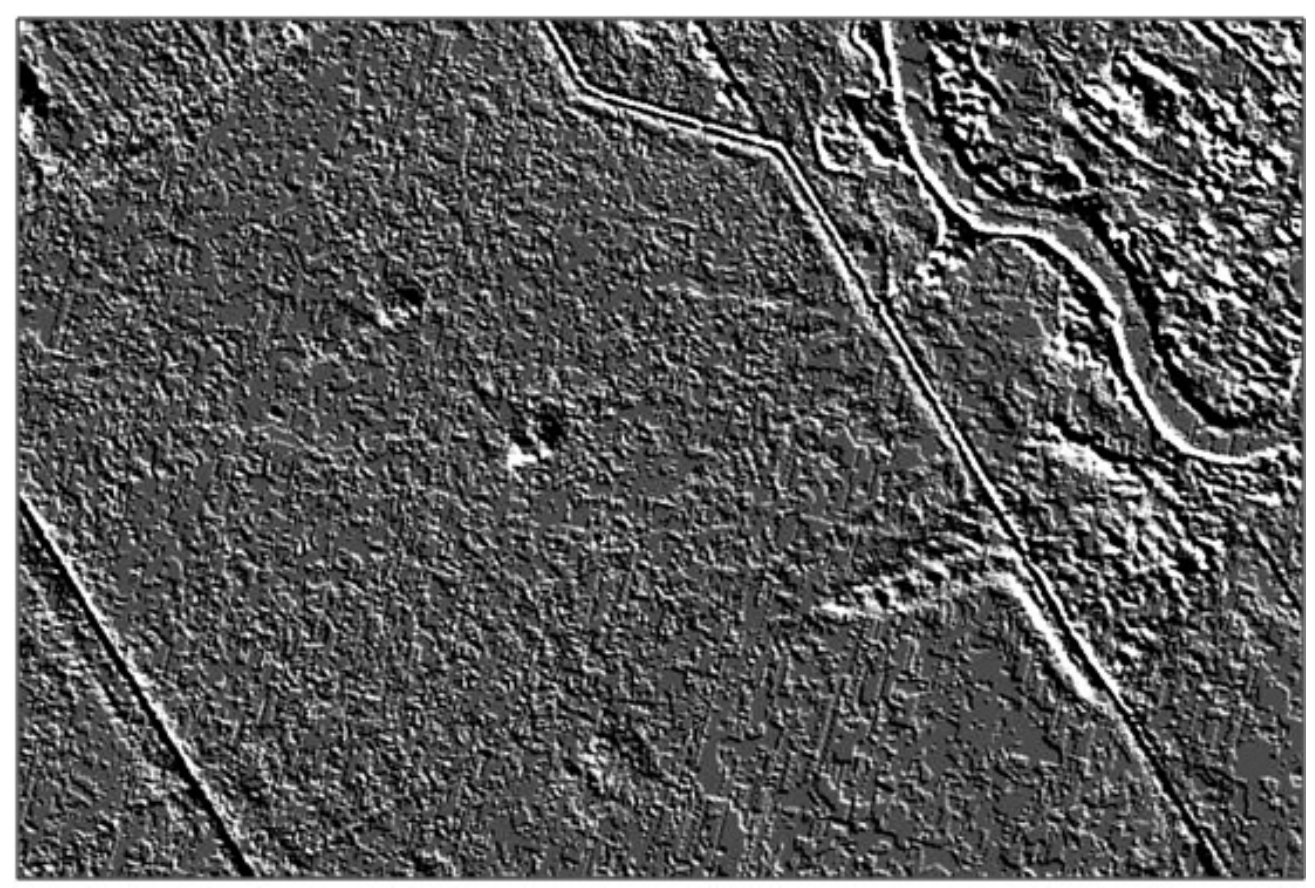

Figura 3. Imagen pancromática con aplicación de filtro direccional y procesos de inversión y realice de brillo y contraste 
En la última imagen de esta serie (Figura 4) se presentan tres puntos con las coordenadas geográficas en grados, minutos y segundos, que permitan la contrastación del rasgo en el terreno. Cabe destacar que las coordenadas pueden no ser exactas, sino aproximadas.

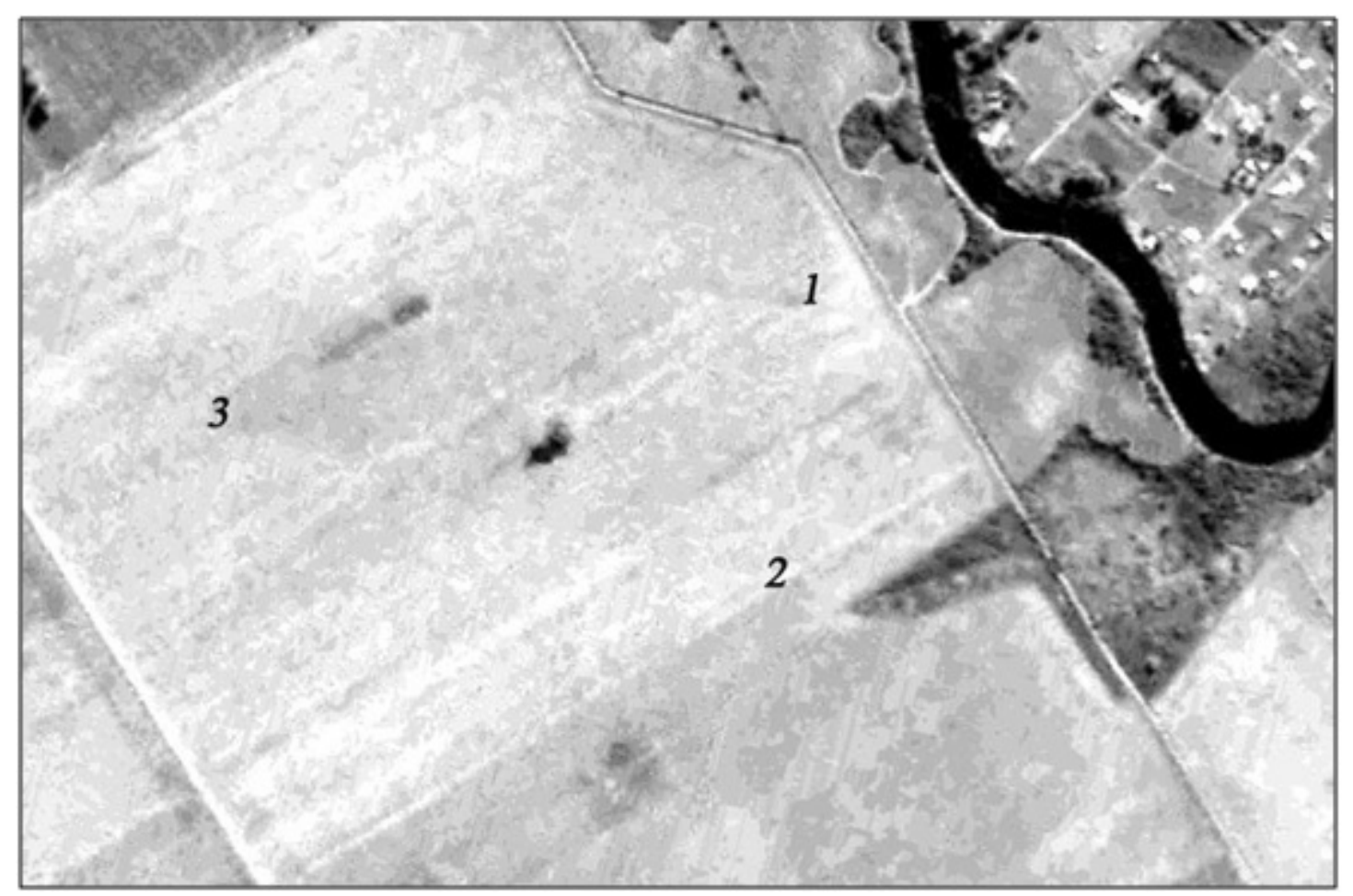

Figura 4. Coordenadas geográficas de tres puntos del supuesto rasgo identificado

Cabe resaltar que el rasgo identificado no pudo ser reconocido en otras imágenes, entre ellas: en imagen pancromática de Landsat 7 ETM+ (con resolución espacial de $15 \mathrm{~m}$ ) e incluso en imágenes del Google Earth (espectro visible de aproximadamente $2 \mathrm{~m}$ de resolución espacial). Esta falta de reconocimiento en otras imágenes, especialmente en la pancromática de Landsat (es decir, con similar sensibilidad radiométrica y espectral del sensor) se puede explicar por, al menos, dos cuestiones:

1. La diferencia en la "sensibilidad" de sensor. CBERS 2B HRC pancromática posee una resolución espectral entre 0,50 y $0,80 \mu \mathrm{m}$, mientras que la pancromática de Landsat abarca un espectro entre 0,52 y 0,90 $\mu \mathrm{m}$. En cambio, las imágenes del Google Earth utilizan únicamente el espectro visible (aproximadamente entre 0,44 y $0,70 \mu \mathrm{m}$ ) y además ya se encuentran procesadas en un único canal. A esto hay que agregarle el hecho que la resolución espacial de la imagen Landsat 7 ETM+ es de $15 \mathrm{~m}$ en contraposición con la imagen del CBERS 2B HRC de 2,7 m (es decir que esta última puede identificar rasgos u objetos más pequeños que la primera).

2. La calidad de la imagen. Las imágenes CBERS 2B no poseen la misma calidad que las Landsat debido a que las primeras tienen ciertas zonas retocadas con posterioridad al momento de la toma. Esto resulta en imágenes con menor fidelidad visual.

\section{Zona de interés 2}

Esta zona se encuentra un poco más al sur del rasgo previamente identificado. La detección del rasgo se logró analizando una imagen pancromática de Landsat 7 ETM+. En la Figura 5 se presenta la imagen original. 


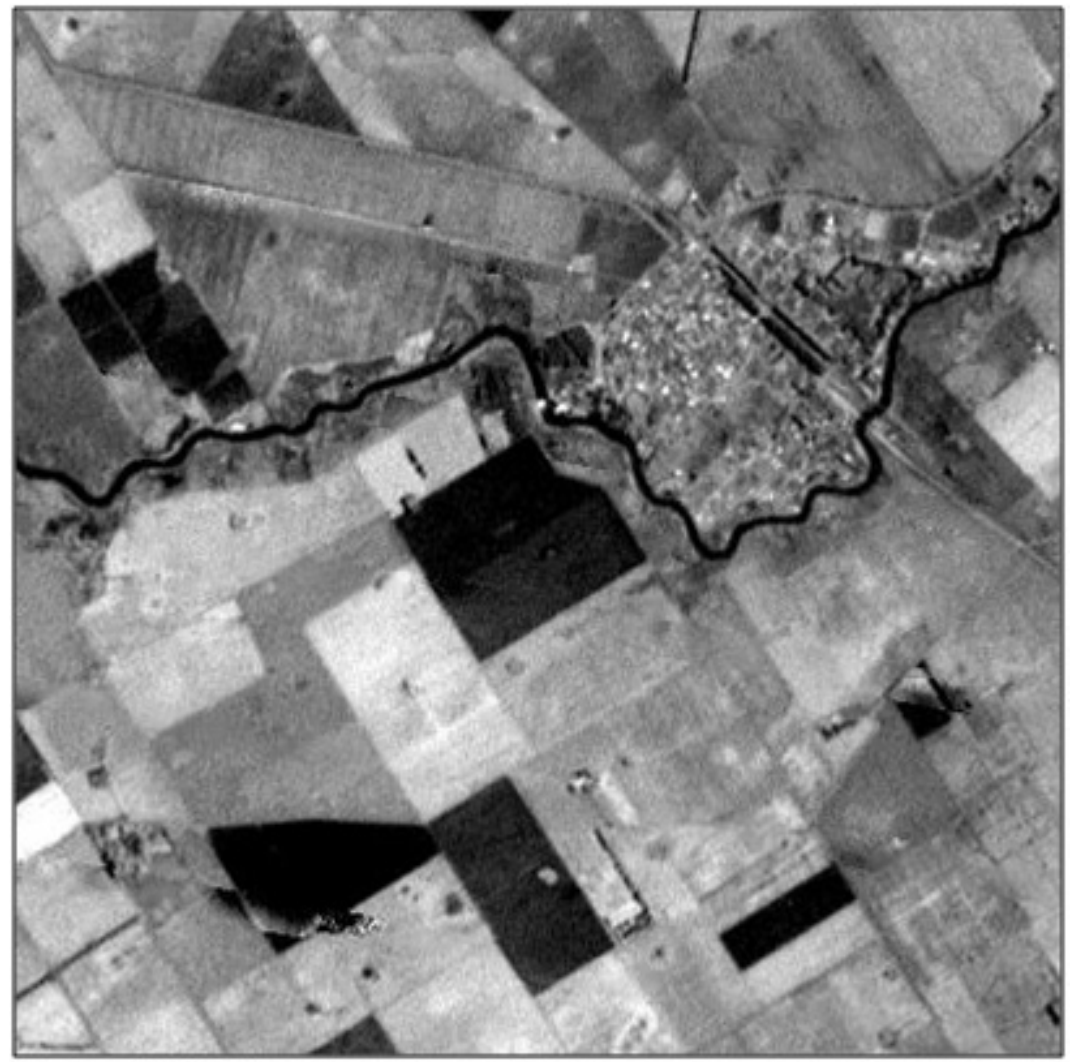

Figura 5. Pancromática de Landsat 7 ETM+ con el rasgo de interés en el recuadro

Sobre la imagen de la figura anterior se realizó el análisis digital (Figura 6). En este caso el análisis secuencial se comenzó con la aplicación de un filtro adaptativo denominado Lee. Los filtros adaptativos se basan en el uso del desvío estándar de los píxeles circundantes a fin de calcular un nuevo valor de cada pixel, resultando muy útil para preservar formas y disminuir el "ruido" de la imagen (Bognanni, 2015). Particularmente el filtro Lee reduce el moteado ("speckle") de los datos que están relacionados con la intensidad de la imagen y además posee un componente aditivo y/o multiplicativo. De esta forma se preserva la forma y los detalles (de las estructuras identificadas) pero se elimina el ruido (Lee, 1980). Seguido a esto se realizó una mejor basada en el brillo y contraste.

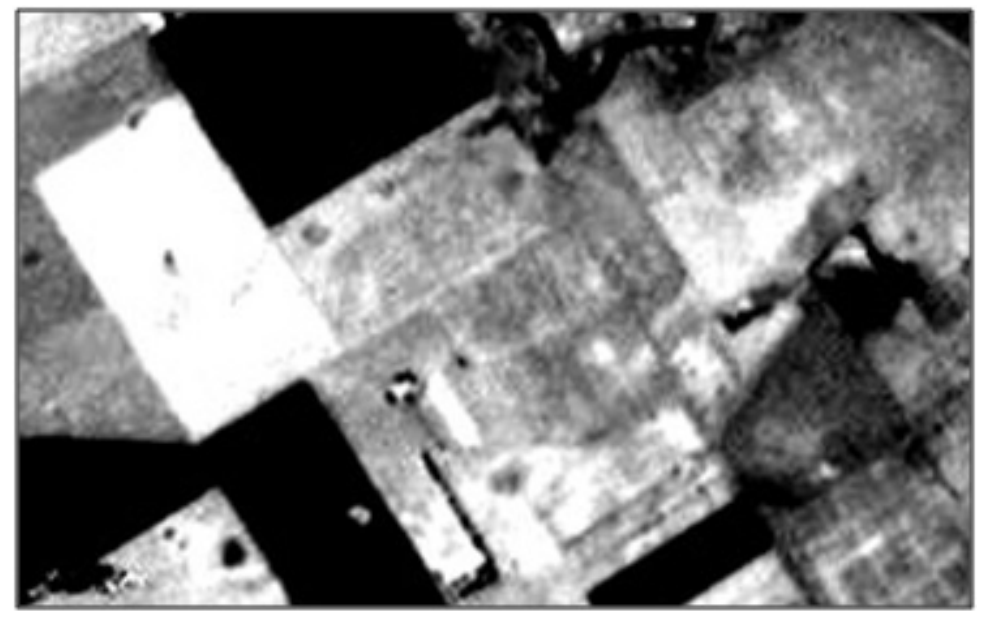

Figura 6. Pancromática de Landsat 7 ETM+ con aplicación de filtro Lee y mejoramiento en brillo y contraste 
En esta imagen se logra identificar un rasgo lineal en un campo arado (más precisamente en forma de "L" invertida y recostada sobre su eje mayor) que no pudo ser identificada en otras imágenes, incluso en las de Google Earth que poseen una excelente resolución espacial. El rasgo parece demasiado grande para ser una iglesia u otra estructura habitacional, sin embargo nada de esto puede ser descartado. En la imagen siguiente (Figura 7) se presentan las coordenadas (siempre aproximadas, no exactas) para su posterior identificación en el terreno.

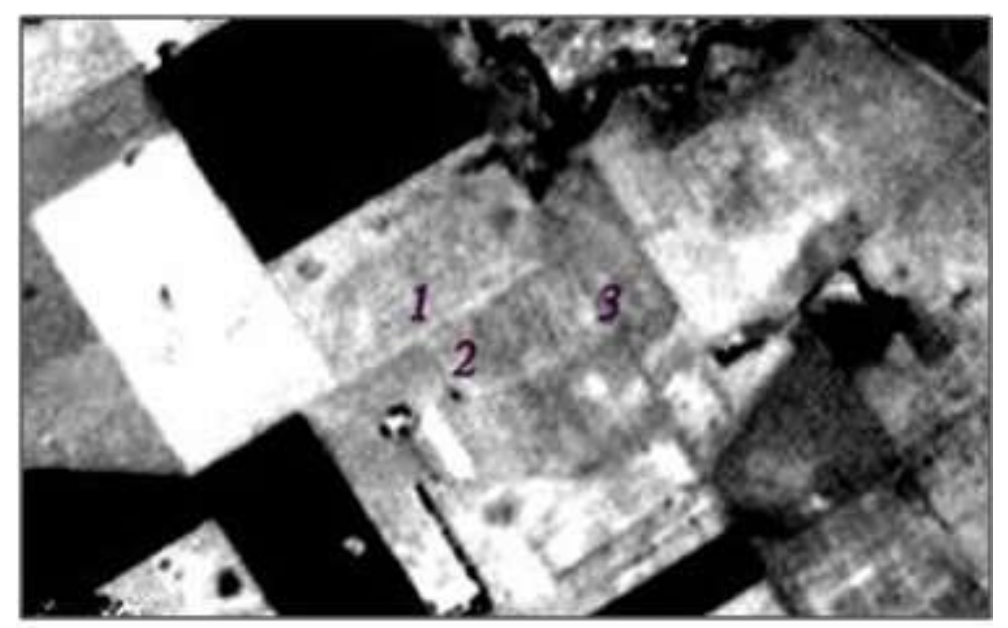

Figura 7. Coordenadas geográficas de tres puntos del supuesto rasgo identificado

\section{Zona de interés 3}

Al sudoeste de la zona de interés 1 y al noroeste de la zona 2, se encuentra un tercer lugar que presenta rasgos que podrían vincularse con la estructura del contexto buscada. En la Figura 8 se presenta el lugar en cuestión.

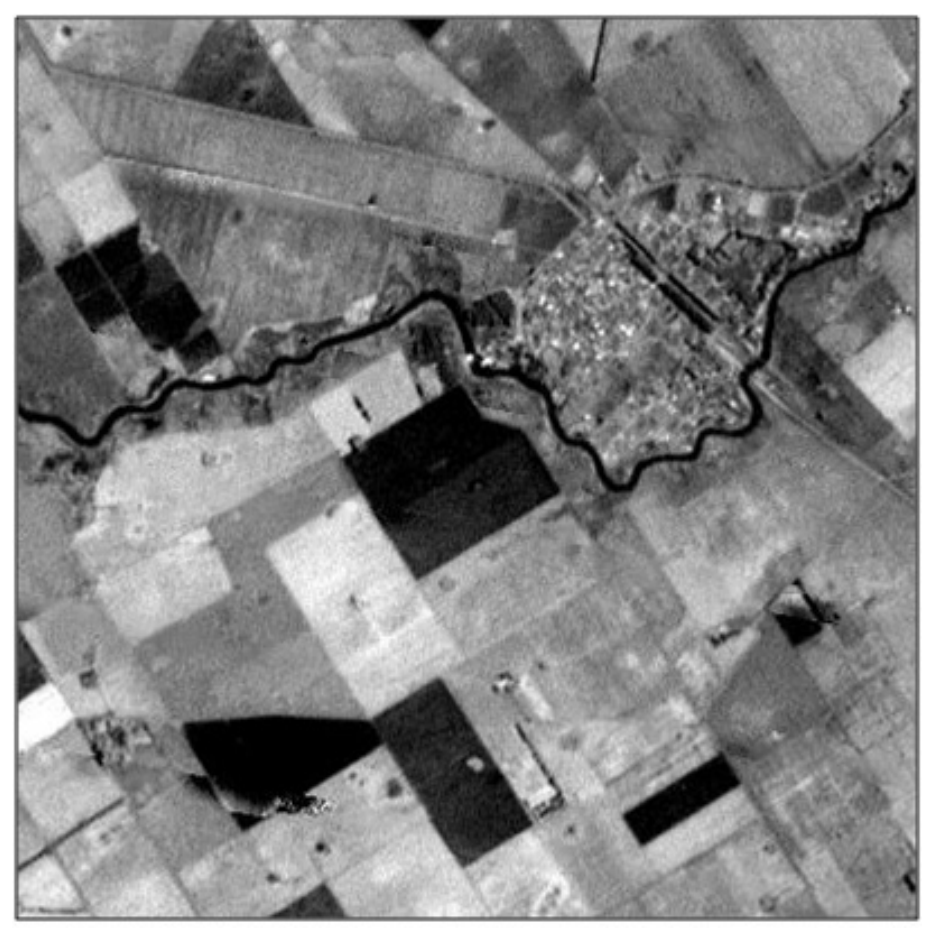

Figura 8. Pancromática de Landsat 7 ETM+ con el rasgo de interés en el recuadro 
Sobre la imagen pancromática anterior se aplicó un procedimiento de análisis de textura que se basa sobre la varianza. Estos filtros actúan sobre la uniformidad de intensidad de la imagen y sus variaciones. Esta uniformidad resulta en un ordenamiento de píxeles (en escala de grises) que se presentan en forma repetida y no casual conformando una estructura de características similares que se observa sobre la imagen como textura. Esta repetición espacial de patrones se puede filtrar, mediante el software ENVI, a través de su matriz de ocurrencia. Al utilizar la varianza, se actúa sobre la medida de contraste del nivel de gris que se utiliza para establecer descriptores de suavidad relativa (Nadales Pérez, 2006 /2007). En la Figura 9 se presenta el resultado de la aplicación de esta técnica. Allí se evidencia un rasgo rectangular de aproximadamente 350 por $250 \mathrm{~m}$. Cabe mencionar que el rasgo no se observa en imágenes constituidas a partir del espectro visible como por ejemplo, Google Earth o ciertas bandas de Landsat 7 ETM+. En cambio, sí se logra identificar (aunque con cierta dificultad) en combinaciones de bandas que utilizan parte del espectro infrarrojo medio y cercano. En la Figura 10 se observa el mismo rasgo utilizando las combinaciones de bandas RGB 754 del satélite Landsat 7 ETM+. Esta combinación, al no contener bandas del espectro visible, permite una mayor penetración atmosférica y proporciona buenas posibilidades de identificar cambios de textura y humedad del suelo (Bognanni, 2015).

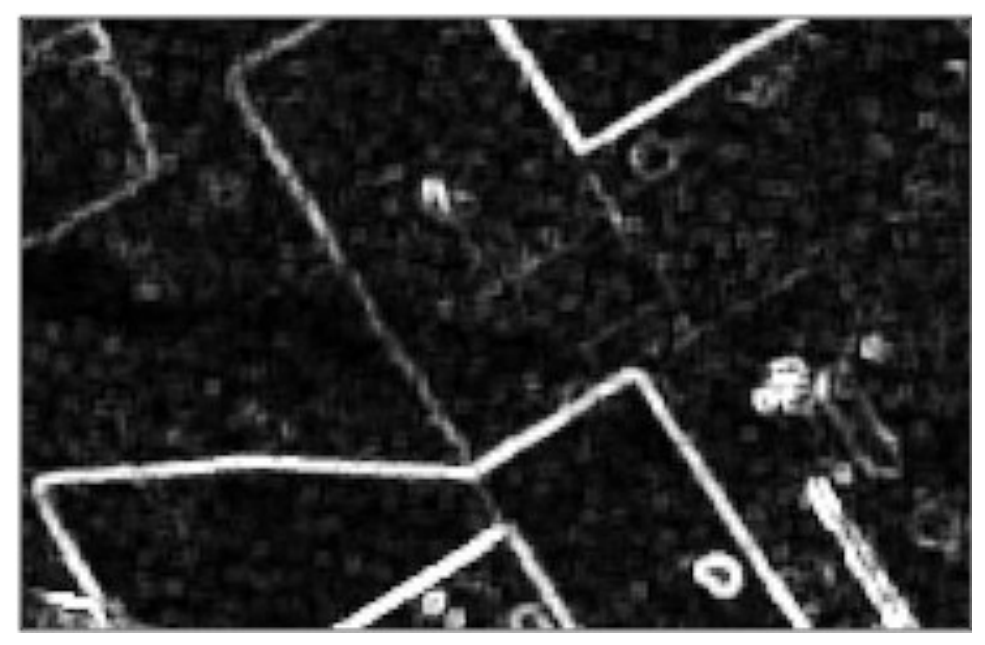

Figura 9. Pancromática de Landsat 7 ETM+ con aplicación de filtro de ocurrencia de textura sobre la varianza

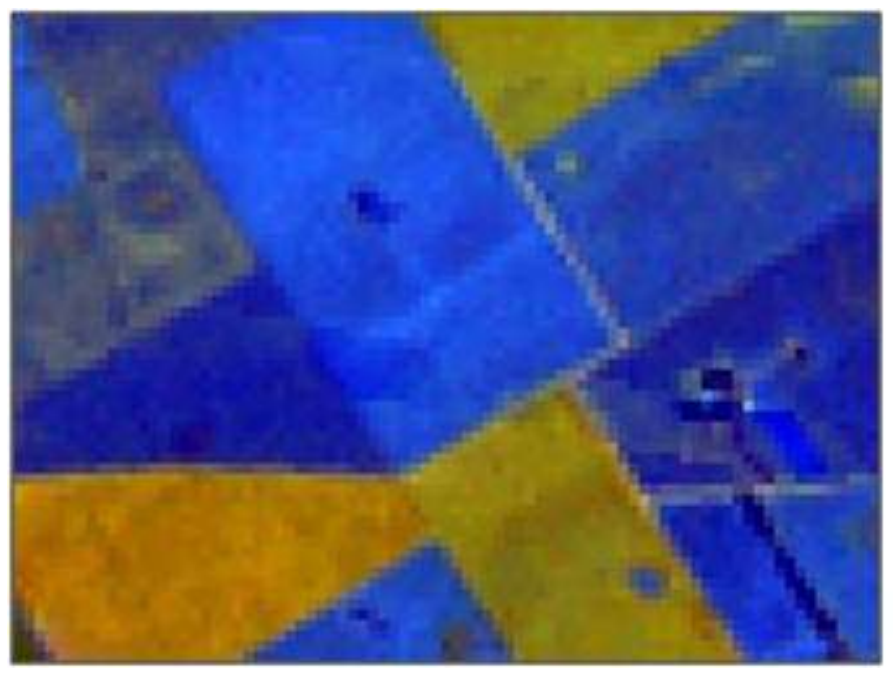

Figura 10. Combinación de bandas 754 de Landsat 7 ETM+ 
En la imagen siguiente (Figura 11) se presentan tres puntos con las coordenadas geográficas a fin de poder ubicar el rasgo en el terreno y contrastar la identificación.

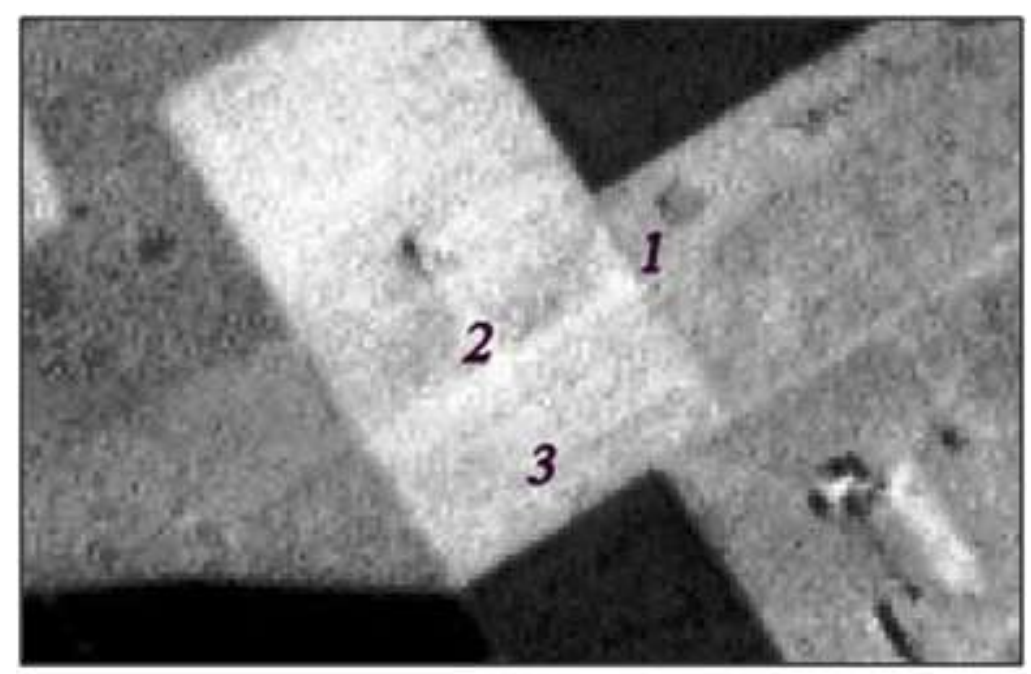

Figura 11. Coordenadas geográficas de tres puntos del supuesto rasgo identificado

\section{Otros rasgos de posible interés identificados a través de Google Earth}

Google Earth es una herramienta formidable para la identificación de rasgos no por sus características espectrales (ya que son imágenes formadas dentro del espectro visible y que ya se encuentran procesadas por el comercializador del software) sino por su alta resolución espacial. Estas imágenes pueden tener una resolución espacial en sus sensores multiespectrales de entre 1,65 m (satélite Geoeyes 1) a 2,4 m (satélite Quickbird) e incluso mejores en sus bandas pancromáticas (no accesibles de forma gratuita).

Por lo expuesto, es que la realización de un análisis visual sistemático puede revelar ciertos rasgos de interés para contrastar en el terreno. A continuación se presentan una serie de estos rasgos.

La Figura 12 presenta la imagen general con las zonas de interés para relevar en el terreno.

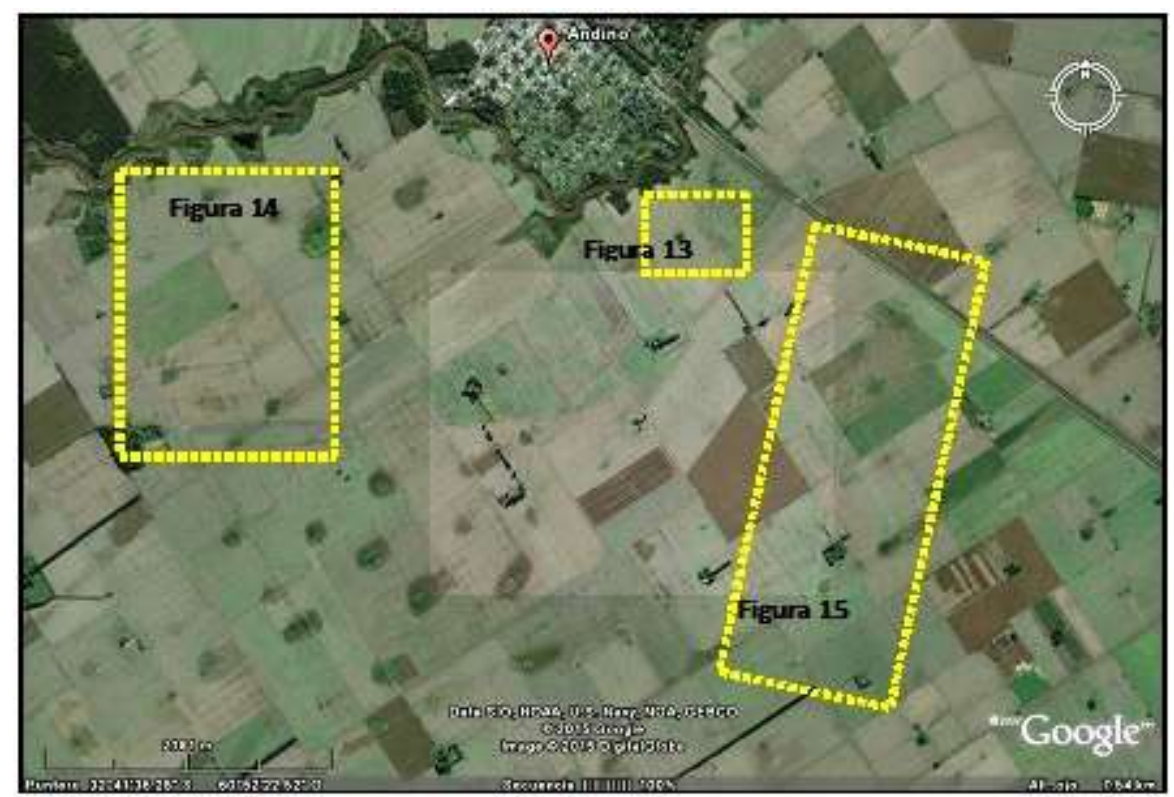

Figura 12. Imagen GoogleEarth con las zonas de interés identificadas 
En la Figura 13 se observa un rasgo rectangular de unos 120 por $60 \mathrm{~m}$ afectado por un pequeño cúmulo de árboles. El rasgo parece remarcarse por una acumulación de humedad en el terreno. Se establecieron cuatro puntos con coordenadas, en cada ángulo del rectángulo, para su ubicación en el terreno.

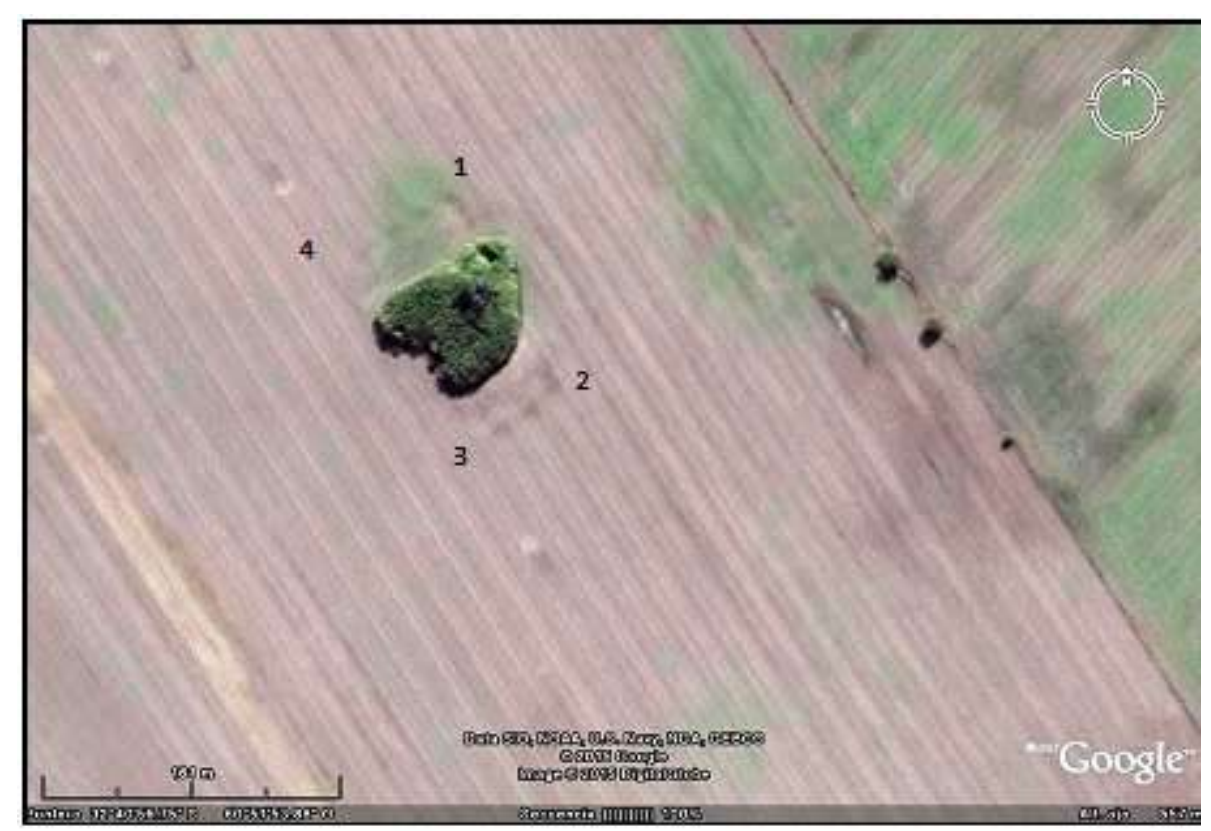

Figura 13. Google Earth. Rasgo rectangular. Los números son puntos de coordenadas para su ubicación en el terreno

La siguiente imagen (Figura 14) obviamente, por sus dimensiones, no podría representarlos restos de una construcción, como una iglesia u otra estructura similar, pero podría corresponderse con una antigua zona de cultivos (sobre todo teniendo en cuenta que esta actividad agrícola debió llevarse a cabo en tiempos de la Estancia Jesuita). De todas formas, lo que se observa es una concentración lineal de humedad con otros rasgos lineales, paralelos y perpendiculares. Al igual que en casos anteriores, el trabajo de campo es ineludible.

Se establecieron cuatro puntos con coordenadas, en cada ángulo del rectángulo, para su ubicación en el terreno.

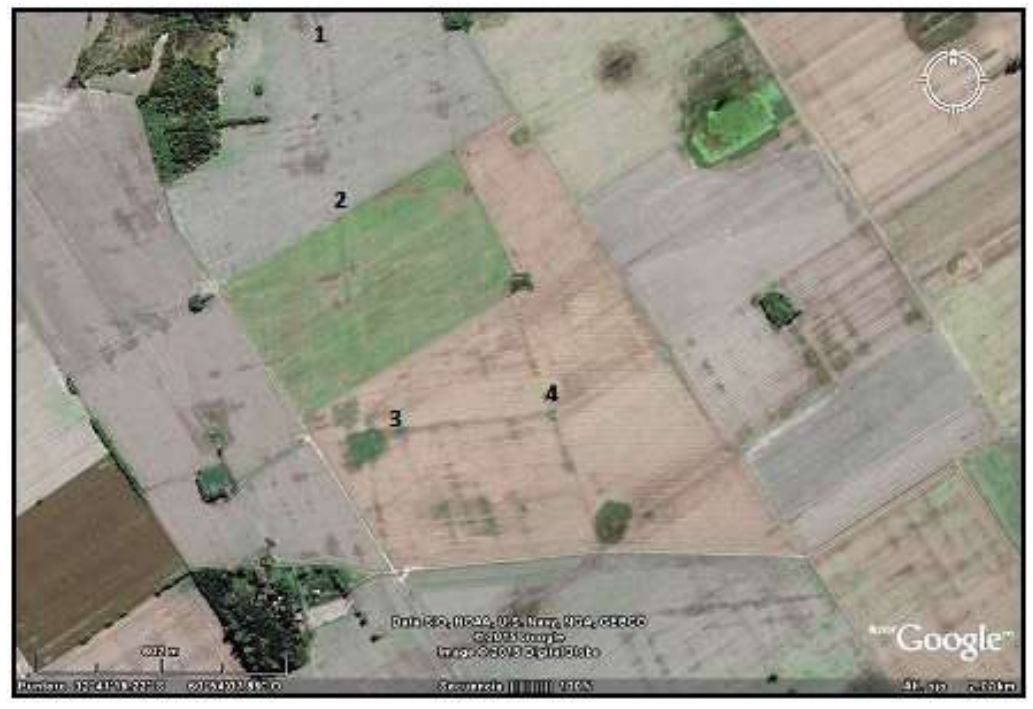

Figura 14. GoogleEarth. Rasgos lineales. Los números son puntos de coordenadas para su ubicación en el terreno 
La imagen 15, al igual que la anterior, no podría ser la iglesia buscada pero podría ser algún elemento asociado al contexto de estudio. Este es un rasgo lineal que, en el segmento de la imagen presentado, posee unos $3 \mathrm{~km}$ de longitud aunque el rasgo continúa hacia el sudoeste por varios $\mathrm{km}$ más, aunque con algunos cambios en su dirección. El rasgo parece corresponderse con un camino en desuso e incluso sedimentado y arado en su superficie.

Se establecieron dos puntos con coordenadas, cada uno en el cruce con un camino existente para hacer más fácil su ubicación en el terreno (se recuerda que las coordenadas pueden no ser exactas, sino más bien aproximadas). En este caso se recomienda hacer la observación en el terreno con luz rasante, es decir en el atardecer o amanecer, para tener un mayor contraste de los posibles desniveles del terreno.

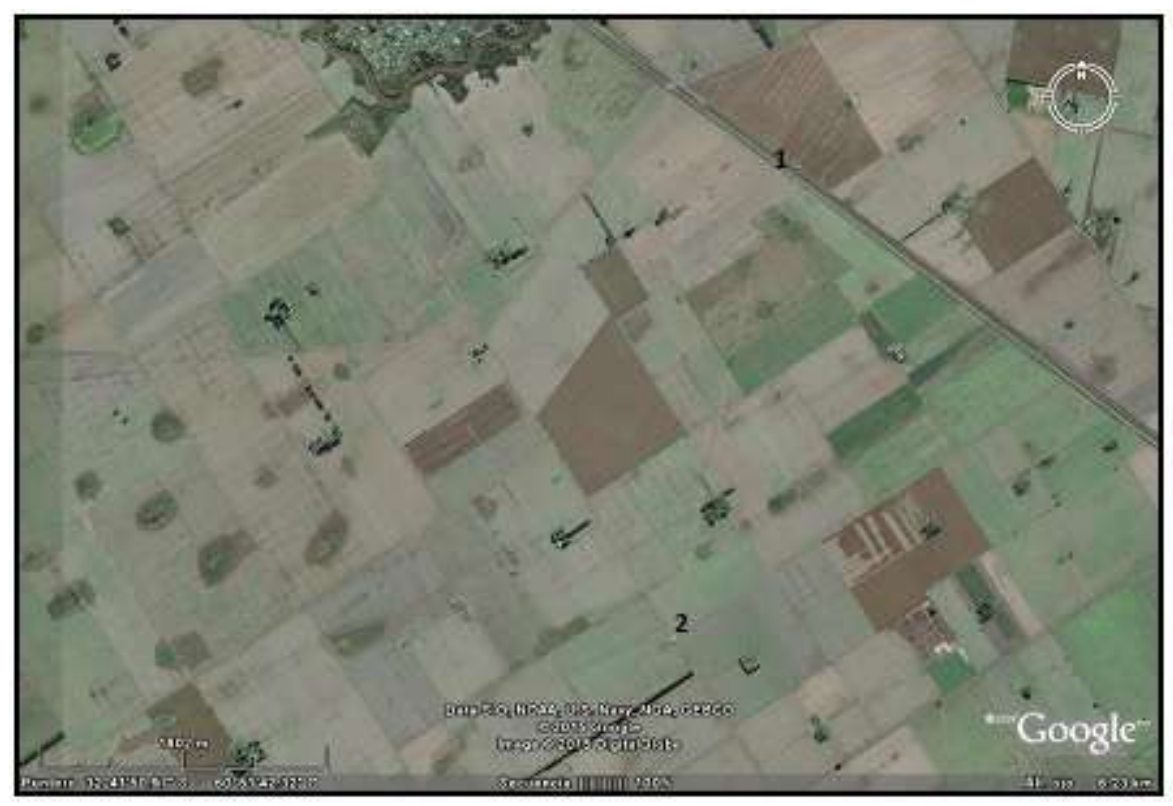

Figura 15. Google Earth. Rasgo lineal, posiblemente un antiguo camino. Los números son puntos de coordenadas para su ubicación en el terreno

\section{Consideraciones finales}

El sitio y su red están vertebrados bajo la norma del estado, que organiza y otorga incumbencias, genera derechos y obligaciones a cada uno de los sujetos que integran la red. Así es que se cumplieron todas las formas que la norma indica cuando se pretende excavar un sitio arqueológico en Argentina. A pesar de los esfuerzos y acuerdos llevados adelante entre el actor privado, dueño del campo, y el equipo de investigación, ha sido prácticamente imposible realizar excavaciones extensas en el predio, especialmente porque el privado no permite el acceso sin el cobro del costo del rinde agrícola que le otorgaría el sector a excavar. La dialéctica (Rocchietti 1998) mencionada anteriormente como idea teórica se plasma en coyuntura cotidiana cuando un proyecto de investigación aprobado y avalado ve limitado su trabajo por años sobre la base de relaciones de poder que priorizan lo económico. El campo en cuestión, es un sembradío de soja.

Este tipo de análisis a través de las tecnologías de teledetección nos permiten ser más precisos a la hora de intervenir en el sitio, incluso pensando en el tiempo y espacio al actuar y también en la preocupación del privado en el rinde económico. 
La idea de implementar estos análisis nos dan la posibilidad de pensar en trabajos a futuro que resuelvan o minimicen las intervenciones y así convenir una nueva relación entre el dueño del predio y la investigación. Seguiremos intentando...

\section{Referencias}

BOGNANNI, F. (2015). Un estudio acerca del uso del espacio en arqueología de sitios históricos. "Corrales de indios" y rastrilladas: un análisis interregional. Provincias de Buenos Aires y Mendoza. British Archaeological Report, International Series 2710 (Archaeopress and F. A. Bognanni), Oxford.

CHUVIECO, E. (1990). Fundamentos de teledetección espacial. Ediciones Rialp, Madrid.

CONOLLY, J. y LAKE, M. (2009). Sistemas de información geográfica aplicados a la arqueología. Bellaterra ediciones, Barcelona.

GEBHARD, J. (2002). Introducción al procesamiento digital de imágenes. Cátedra de Aero foto interpretación, FCN y M, UNLP. La Plata. Ms.

LEE, J. (1980). Digital image enhancement and noise filtering by use of local statistics. IEEE Transactions on Pattern Analysis and Machine Intelligence, Vol. PAMI-2, N 2, March, 165-168.

NADALES PÉREZ, F. (2006/2007). Detección de áreas urbanas en imágenes de satélite SAR en China. (Proyecto de Grado), Universidad Politécnica de Cartagena.

Recibido: 10/05/2017

Aceptado: 27/08/2017 